\title{
A aplicação da Convenção da UNESCO de 1972 sobre a Proteção do Patrimônio Cultural e Natural da Humanidade pelo STJ em bem particular tombado pelo Poder Público: análise do RESP n ${ }^{0}$ 1791098/RJ
}

\author{
Comentário de Jurisprudência
}

\author{
Ivonei de Souza Trindade 1
}

\begin{abstract}
PROCESSUAL CIVIL. PATRIMÔNIO HISTÓRICO-CULTURAL. ART. $1.228, \S 1^{\circ}$, DO CÓDIGO CIVIL. ART. 19, CAPUT E $\S 3^{\circ}$, DO DECRETOLEI 25/1937. FUNÇÃO MEMORATIVA DO DIREITO DE PROPRIEDADE. OBRIGAÇÕES DO PROPRIETÁRIO E DO ESTADO. CONVENÇÃO RELATIVA À PROTEÇÃO DO PATRIMÔNIO MUNDIAL, CULTURAL E NATURAL DA UNESCO. CIDADE DO RIO DE JANEIRO. IMÓVEL TOMBADO. LIMITAÇÃO ADMINISTRATIVA. ÔNUS DA PROVA DA FALTA DE CONDIÇÕES FINANCEIRAS PARA A RESTAURAÇÃO. MULTA CIVIL JUDICIAL TARIFADA. OFENSA AO ART. 489 DO CPC/2015 CONFIGURADA.
\end{abstract}

1. Cuida-se, na origem, de Ação Civil Pública proposta pelo Ministério Público contra o Estado do Rio de Janeiro e o proprietário de bem tombado, integrante do "Conjunto Arquitetônico e Urbanístico da Rua Martins Ferreira e Adjacências", localizado no Bairro de Botafogo. O Parquet pleiteia a condenação dos réus a: a) executarem obras de recuperação e restauração dos imóveis; b) pagarem indenização por danos morais coletivos.

2. A proteção do patrimônio histórico-cultural, bem da Nação, é direito de todos e dever do proprietário e do Estado. Não se trata de modismo fortuito ou mero favor vanguardista em benefício da coletividade, mas de ônus inerente ao âmago do domínio e da posse em si, inafastável condição absoluta para sua legitimidade e reconhecimento pelo ordenamento jurídico. Com base nessa obrigação primária, decorrente da função memorativa do direito de propriedade, incumbe ao Estado instituir, in concreto, eficaz regime de limitações administrativas, portador de obrigações secundárias ou derivadas, utilizando-se, para tanto, de instrumentos variados, entre os quais o tombamento.

3. As obrigações que compõem a ordem pública do patrimônio histórico e cultural derivam de princípios gerais do direito e de normas nacionais (federais, estaduais e municipais, inclusive constitucionais) e internacionais. Na legislação brasileira, sobressaem o Decreto-Lei 25/1937 e o próprio Código Civil, que expressamente inclui, entre as "finalidades

1 Professor Assessor de Direito Internacional dos Direitos Humanos no A Pari MUNInstituto de Investigación y Debate en Derecho (Nuevo Chimbote, Peru). Possui graduação em Direito pela Pontifícia Universidade Católica do Rio Grande do Sul (2013). Membro Associado da Société Québécoise de Droit International (2016 - atualmente). Advogado. 
econômicas e sociais" do direito de propriedade, a preservação do "patrimônio histórico e artístico" (art. 1.228, § 1). Ademais, há tratados internacionais sobre a matéria, como a Convenção Relativa à Proteção do Patrimônio Mundial, Cultural e Natural, aprovada pela Conferência Geral da Unesco, realizada em Paris, de 17 de outubro a 21 de novembro de 1972, e recepcionada entre nós pelo Decreto Legislativo 74/1977 (confirase, especificamente, o art. $4^{\circ}$, que prevê a obrigação estatal de "identificar, proteger, conservar, valorizar e transmitir às futuras gerações o patrimônio cultural e natural").

4. A jurisprudência do STJ é pacífica no sentido de que incumbe ao titular da propriedade ou da posse o dever primeiro de conservar o bem tombado, sem excluir correlato dever do Poder Público, instituidor do tombamento e garantidor maior do patrimônio histórico e cultural da Nação. A hipótese é, pois, de responsabilidade civil de imputação solidária e execução subsidiária, pela qual desrespeito às normas de regência da matéria impõe condenação conjunta do proprietário e do Estado, executado este somente se o particular "não dispuser de recursos para proceder às obras de conservação e reparação" (art. 19, caput, do Decreto-Lei 25/1937). Precedentes: AREsp 176.140/BA, Rel. Ministro Castro Meira, Segunda Turma, DJe de 26/10/2012; REsp 895.443/RJ, Rel. Ministra Eliana Calmon, Segunda Turma, DJe 17/12/2008; REsp: 1.184.194/RS, Rel. Ministra Eliana Calmon, Segunda Turma, DJe de 22/9/2010. Obviamente, o benefício de ordem desaparece quando verificada "urgência na realização de obras e conservação ou reparação" (art. 19, § $3^{\circ}$ ), ressalvado nesse caso o direito de regresso do ente público.

5. Se o proprietário do bem tombado não contar com meios financeiros para medidas de conservação e reparação de rigor, dele se exige que: a) leve ao conhecimento do órgão competente do patrimônio histórico e cultural a necessidade das obras, sob pena de multa civil tarifada, a ser aplicada pelo juiz, "correspondente ao dobro da importância em que for avaliado o dano sofrido" pelo bem (art. 19, caput, do Decreto-Lei 25/1937), além de outras sanções administrativas e penais incidentes e da responsabilidade civil por eventuais prejuízos materiais e morais que da ação ou omissão decorram; b) demonstre cabalmente a ausência de recursos próprios, pois trata-se de onus probandi que, por óbvio, lhe incumbe.

6. Observa-se, como aduz o Estado do Rio de Janeiro, que o proprietário do imóvel em momento algum provou incapacidade econômico-financeira para conservar o bem tombado, deixando, por outro lado, de cumprir a indispensável providência fixada no art. 19, caput, do Decreto-Lei 25/1937 (informar, prévia e formalmente, à Administração Pública). O aresto vergastado não explicitou as razões, lastreadas em provas dos autos, que levaram o Tribunal a concluir pela incapacidade financeira do proprietário, matéria relevante para o deslinde da controvérsia.

7. Recurso Especial do Estado do Rio de Janeiro provido para anular o aresto proferido nos Embargos de Declaração e determinar o retorno dos autos ao Tribunal de origem para que profira novo julgamento e aborde a matéria omitida, acima descrita. Agravo em Recurso Especial do Ministério Público do Estado do Rio de Janeiro não conhecido, por incidência da Súmula 7/STJ.

SUPERIOR TRIBUNAL DE JUSTIÇA. REsp 1791098/RJ. Rel. Ministro Herman Benjamin. Segunda Turma, julgado em: 23/04/2019. Publicano no DJe em: 02/08/2019. 


\section{Resumo do Caso}

O caso versa sobre uma ação civil pública promovida pelo Ministério Público do Estado do Rio de Janeiro (MPE-RJ) contra o proprietário de um bem tombado e o Estado do Rio de Janeiro pedindo, de maneira solidária a ambas partes no polo passivo, a restauração do imóvel bem como uma indenização pelos danos ocasionados. O imóvel tombado é integrante do Conjunto Arquitetônico e Urbanístico da Rua Martins Ferreira e Adjacências, no bairro Botafogo, na cidade do Rio de Janeiro. O Tribunal de Justiça do Rio de Janeiro (TJ-RJ) condenou somente o Estado do Rio de Janeiro a realizar a reparação do imóvel bem como a pagar a indenização.

Em recurso ao Superior Tribunal de Justiça (STJ), o Estado do Rio de Janeiro alegou que o TJ-RJ não avaliou a posição econômica nem a ausência de manifestação do corréu - no caso, o proprietário do imóvel. Com base nisso, o Estado do Rio de Janeiro defendeu que a decisão do TJ-RJ violava o Decreto-Lei do Tombamento (Decreto-Lei $\mathrm{n}^{0}$ 25/1937), ao ignorar o proprietário do imóvel tombado, pois este possui responsabilidade primeira na conservação do bem.

O Ministro Herman Benjamin, relator do caso no STJ, acolheu a defesa do Estado do Rio de Janeiro e asseverou que é dever primeiro do proprietário em conservar e proteger um patrimônio tombado sob seus cuidados e, caso não tenha recursos financeiros, deve realizar a comunicação às autoridades públicas estatais responsáveis pela proteção do patrimônio cultural. O seu voto ainda ressaltou que o Estado segue tendo a obrigação de preservar, identificar e zelar do seu patrimônio cultural, de modo que ambas as partes (Estado e proprietário particular, caso haja) possuem responsabilidade solidária neste referido dever. A turma da Corte Superior seguiu por unanimidade a posição do relator (STJ, 2019).

Merece destaque neste julgamento a menção do STJ ao artigo $4^{\circ}$ da Convenção da UNESCO de 1972 sobre a Proteção do Patrimônio Cultural e 
Natural da Humanidade, que estabelece o dever estatal de "identificar, proteger, conservar, valorizar e transmitir às futuras gerações o patrimônio cultural e natural". A referência da Corte é breve, sem maiores explicações nem análise pormenorizada deste dispositivo legal.

Pela lacuna da explicação do STJ quanto ao uso do $4^{\circ}$ da Convenção de 1972, este texto procurará fazer uma análise do mencionado dispositivo legal bem como deste tratado frente ao caso julgado.

\section{Comentários à decisão do STJ}

A análise feita, a partir daqui, será norteada por normas do Direito Internacional do Patrimônio Cultural - especificamente, a Convenção da UNESCO de 1972 sobre a Proteção do Patrimônio Cultura e Natural da Humanidade - e não focará em áreas do Direito interno como Direito Civil e Direito Administrativo, por exemplo. Antes dos comentários, deve ser feita uma breve contextualização de como o Brasil está inserido na proteção do patrimônio cultural dentro do Direito Internacional.

A Convenção de 1972 foi ratificada pelo Brasil, sendo este tratado internalizado ao ordenamento jurídico brasileiro em junho de 1977 através do Decreto Legislativo $\mathrm{n}^{0}$ 74/1977(BRASIL, 1977) com o depósito feito três meses depois na UNESCO. (UNESCO, 2020). Segundo o texto do mencionado decreto, houve ressalva brasileira quanto ao parágrafo primeiro do artigo 16, ponto que trata da contribuição dos Estados Partes, a cada dois anos, ao Fundo do Patrimônio Mundial.

O tratado da UNESCO criou o Comitê do Patrimônio Mundial, órgão responsável por identificar e reconhecer os patrimônios da humanidade indicados pelos Estados Partes da Convenção de 1972 com excepcional valor universal. O Brasil, eleito em 2017 para a composição desse órgão (NAÇÕES UNIDAS, 2017), tem mais de vinte patrimônios da humanidade reconhecidos por esse comitê (UNESCO, 2020). 
Em 2012, o Rio de Janeiro teve sua paisagem natural e urbanística reconhecida como Patrimônio da Humanidade pelo Comitê do Patrimônio Mundial da UNESCO. O reconhecimento teve como alvo os seguintes pontos: 1) Parque Nacional da Tijuca (Floresta da Tijuca, Pretos Forros, Covanca, Pedra Bonita, Serra da Carioca e Pedra da Gávea); 2) Jardim Botânico; 3) Baía de Guanabara (Flamengo, Fortes Históricos de Niterói, Pão de Açúcar, Copacabana e Leme). (BRAZIL, 2011, p.16).

O imóvel objeto deste caso do STJ está localizado no bairro Botafogo, ou seja, não está na área dentro do Rio de Janeiro reconhecida pela UNESCO como patrimônio da humanidade. O artigo $4^{\circ}$ da Convenção de 1972 segue válido para esta situação mesmo assim? A resposta é sim, pois o artigo $4^{\circ}$ da Convenção de 1972 estabelece uma obrigação aos Estados de preservação, de identificação e de proteção do seu patrimônio cultural e natural. $\mathrm{O}$ dispositivo não faz menção se este dever é relacionado somente aos patrimônios presentes na lista de patrimônios da humanidade da UNESCO, de modo que o seu teor é uma orientação geral aos Estados Partes.

No documento de diretrizes para a implementação do tratado, feito em julho de 2019, a UNESCO ressaltou que os Estados Partes da convenção possuem a obrigação de identificar, conservar e preservar o patrimônio cultural do seu território. Nota-se que a mencionada orientação não restringe este dever àquilo que seria suscetível de inscrição à lista de patrimônios da humanidade da UNESCO. É uma obrigação geral para todo e qualquer patrimônio dentro do Estado Parte. (UNESCO, 2019, p.15)

A partir disso, nota-se que a aplicação do artigo $4^{\circ}$ do referido tratado, portanto, é válida nesta situação, mesmo sendo referente a um lugar que não tenha sido mencionado quando o Brasil lançou a candidatura de lugares do Rio de Janeiro para a lista da UNESCO. Como complemento de fundamentação desta posição, deve ser mencionado o artigo 12 da Convenção de 1972, que estabelece o seguinte: 
Artigo 12. O fato de que um bem do patrimônio cultural ou natural não haja sido incluído numa ou outra das duas listas mencionadas nos parágrafos 2 e 4 do artigo 11 não significará, em absoluto, que ele não tenha valor universal excepcional para fins distintos dos que resultam da inclusão nessas listas.

Os dois parágrafos a que o dispositivo legal se refere tratam de duas listas da UNESCO: a de patrimônios da humanidade e a de patrimônios da humanidade em perigo. Pela leitura deste artigo, interpreta-se que um Estado tem o poder para determinar que um patrimônio cultural ou natural seu tenha um valor universal dentro do seu território, ainda que a UNESCO não reconheça por decisão do Comitê do Patrimônio Mundial. Esse respeito pela soberania dos Estados na identificação do seu patrimônio cultural e natural foi um dos pontos da Convenção de 1972 elogiados pela doutrina de Direito Internacional do Patrimônio Cultural. (FRANCIONI; GORDLEY, 2013, p.15).

Segundo a decisão do STJ, tendo como referência o Decreto-Lei do Tombamento (Decreto-Lei $n^{\circ}$ 25/1937), quem deve proteger em primeiro lugar o patrimônio tombado é o seu proprietário. Se esse referido diploma legislativo brasileiro não existisse, resta o questionamento se essa regra, somada à ausência de deveres estatais de proteção do bem, seria válida com base somente nos ditames do artigo $4^{\circ}$ da Convenção de 1972. Com base no mencionado artigo $4^{\circ}$ da Convenção de 1972, a obrigação lá mencionada é referente a Estados, e não a indivíduos. Logo, o tratado, por si só, não seria um fundamento adequado para sustentar o dever individual exclusivo de proteção do patrimônio cultural.

Na sequência, um novo questionamento merece relevância: o DecretoLei do Tombamento, ao estabelecer deveres do cidadão para proteger e conservar um patrimônio cultural, está em consonância com a Convenção de 1972? A resposta está no artigo $5^{\circ}$ do tratado. Entre as obrigações direcionadas aos Estados Partes expostas no artigo $5^{\circ}$, destacam-se as das alíneas a ("Adotar uma política geral que vise determinar uma função ao 
patrimônio cultural e natural na vida coletiva e integrar a proteção do referido patrimônio nos programas de planificação geral") e d (“Tomar as medidas jurídicas, científicas, técnicas, administrativas e financeiras adequadas para a identificação, proteção, conservação, valorização e restauro do referido patrimônio"). Importante mencionar que o caput desse dispositivo legal também não restringe sua aplicação à lista dos patrimônios da humanidade reconhecidos pela UNESCO.

Acerca da alínea a, quando o Estado adota uma política geral para a função e inserção do patrimônio cultural e natural nos programas de planificação geral, nada impede o estabelecimento de obrigações individuais para a execução dessa proposta. Se o Poder Público decretar medidas para abstenção de certas condutas da população que possam danificar o patrimônio, por exemplo, tal circunstância seria conforme o propósito do tratado.

Um exemplo disso está na praia de Copacabana, onde, segundo legislação municipal do Rio de Janeiro, há uma limitação de altura para construção de prédios com fim de preservação do patrimônio natural. ${ }^{2}$ Notase que esta regra, porém com diferentes determinações em comparação com diplomas legais anteriores, é antiga, pois a primeira legislação que trouxe essa previsão para a praia de Copacabana foi o Decreto-Lei n ${ }^{\circ} 4541 / 1942$, já revogado. (BRASIL,1942)

Quanto à alínea d, o Estado, ao estabelecer normas jurídicas com obrigações individuais para proteção e conservação do patrimônio cultural, não fere a Convenção de 1972 da UNESCO desde que a atuação estatal seja mantida. Esses deveres direcionados aos cidadãos podem ser um complemento da proteção do patrimônio, pois o preâmbulo do tratado expressa sua finalidade de que todos os povos devam atentar ao zelo do seu patrimônio.

\footnotetext{
2 Para maiores detalhes, recomenda-se a consulta da seguinte legislação municipal do Rio de Janeiro: Decreto Municipal nº 3.046/1981, Lei Complementar no 111/2011.
} 
A Convenção de 1972, como referido anteriormente, estabelece deveres aos Estados e não a indivíduos, diretamente. Responsabilizar somente indivíduos - através de legislação nacional que exclua qualquer forma de atuação estatal - pela proteção do patrimônio cultural da humanidade feriria esse tratado, pois o Estado é quem tem o dever primeiro de zelo, de identificação e de preservação do patrimônio.

O STJ utilizou, na sua fundamentação, o Decreto-Lei do Tombamento (Decreto-Lei $\mathrm{n}^{\circ}$ 25/1937), um documento com mais de 80 anos e ainda em vigor (BRASIL, 1937). Com essa constatação, surge o questionamento de como este diploma legal está recepcionado no ordenamento jurídico brasileiro.

Para o Supremo Tribunal Federal (STF), o Decreto-Lei do Tombamento, na sua essência, está de acordo com a Constituição Federal (STF, 2018). Com fins de exemplificar essa assertiva, em março de 2020, o Ministro Edson Fachin reafirmou essa posição ao negar seguimento a um pedido de Arguição de Descumprimento de Preceito Fundamental (ADPF) formulado pela Procuradoria-Geral da República, que buscava questionar alguns dispositivos da referida legislação (STF, 2020).

Com a posição estabelecida pelo STF, resta saber se o artigo 19 do Decreto-Lei do Tombamento, utilizado na decisão do STJ, está em consonância com a Convenção da UNESCO de 1972. Segue o texto do referido dispositivo legal do Decreto-Lei:

Art.19. O proprietário de coisa tombada, que não dispuzer (sic) de recursos para proceder às obras de conservação e reparação que a mesma requerer, levará ao conhecimento do Serviço do Patrimônio Histórico e Artístico Nacional a necessidade das mencionadas obras, sob pena de multa correspondente ao dobro da importância em que fôr (sic) avaliado o dano sofrido pela mesma coisa.

$\S 1^{\circ}$. Recebida a comunicação, e consideradas necessárias as obras, o diretor do Serviço do Patrimônio Histórico e Artístico Nacional mandará executá-las, a expensas da União, devendo as mesmas ser iniciadas dentro do prazo de seis mezes (sic), ou providenciará para que seja feita a desapropriação da coisa. 
$\S 2^{\circ}$. À falta de qualquer das providências previstas no parágrafo anterior, poderá o proprietário requerer que seja cancelado o tombamento da coisa.

$\S 3^{\circ}$.Uma vez que verifique haver urgência na realização de obras e conservação ou reparação em qualquer coisa tombada, poderá o Serviço do Patrimônio Histórico e Artístico Nacional tomar a iniciativa de projetá-las e executá-las, a expensas da União, independentemente da comunicação a que alude êste (sic)artigo, por parte do proprietário.

Antes de prosseguir com a análise do artigo, é preciso observar que o caso do STJ trata de um bem particular, ou seja, que pode ser alienado sem direito de preferência de venda à União, a Estados ou a Municípios, nos termos do Código de Processo Civil de 2015. ${ }^{3}$ Esse tombamento foi realizado, provisoriamente, em 1991, ficando definitivo em 2002 (INEPAC, 2020).

O artigo $4^{\circ}$ da Convenção de 1972, conforme defendido anteriormente, pode ser aplicado em bens não reconhecidos pela lista da UNESCO, pois tal abrangência atende ao objetivo do tratado: proteção do patrimônio cultural por toda a sociedade. Isso significa que a proteção de um bem particular tombado pelo Estado está dentro dessa ideia devendo, por conseguinte, esse dispositivo do tratado também ser considerado no caso julgado pelo STJ.

A obrigação individual estabelecida no caput do artigo 19 do DecretoLei do Tombamento está em acordo com os artigos $4^{\circ}, 5^{\circ}$ da Convenção da UNESCO, pois a atuação estatal é mantida. Os parágrafos do artigo 19 expressam a importância de atuação do Estado, caso o indivíduo não consiga primar pelo seu dever de zelo e também em hipótese de urgência para alguma medida de reparação. Não há nesse dispositivo legal prazo estabelecendo quando o proprietário deve comunicar ao Poder Público a sua incapacidade econômica para realizar reparos, se preciso.

O STJ, ao interpretar este artigo, entendeu que o proprietário possui o dever primeiro de zelo do patrimônio cultural. Pela leitura da Convenção da UNESCO de 1972, em contrapartida, nota-se que essa obrigação recai,

\footnotetext{
${ }^{3}$ O artigo 1072 do Código de Processo Civil de 2015 revogou o artigo 22 do Decreto-Lei do Tombamento.
} 


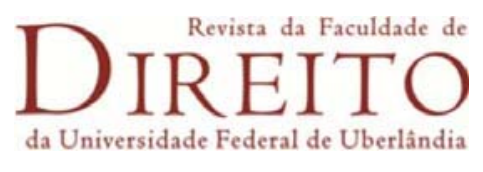

primordialmente, sobre o Estado tanto que o artigo $4^{\circ}$, dispositivo utilizado na decisão, é um reflexo disso ao não trazer obrigações ao indivíduo.

\section{Considerações finais}

É um grande avanço o STJ mencionar a Convenção de 1972 na decisão de um caso que aborda um bem particular tombado pelo Estado do Rio de Janeiro e localizado na capital do referido lugar, que possui pontos reconhecidos como patrimônio da humanidade pela UNESCO. A Corte Superior pecou por não realizar uma análise mais detalhada desse tratado frente à legislação nacional do tombamento, principalmente, quanto à relação de responsabilidade entre Estado e indivíduo frente a um patrimônio cultural.

Conclui-se, apesar da lacuna de posicionamento do STJ quanto a este ponto, que o artigo 19 do Decreto-Lei do Tombamento está de acordo com a Convenção da UNESCO de 1972, tendo em vista que, no referido diploma legal brasileiro, há obrigações estatais previstas para a proteção do patrimônio cultural em sintonia com as disposições do mencionado tratado.

\section{Referências}

BRASIL é um dos 12 países eleitos para Comitê do Patrimônio Mundial da UNESCO. Nações Unidas. 21 de novembro de 2017. Disponível em: https://nacoesunidas.org/brasil-eum-dos-12-paises-eleitos-para-comite-do-patrimonio-mundial-da-unesco/. Acesso em 21 de abril de 2020.

BRASIL. Câmara dos Deputados. Legislação Informatizada - Decreto Legislativo $\mathbf{n}^{\circ}$ 74, de 1977 - Publicação Original. Disponível em: https://www2.camara.leg.br/legin/fed/decleg/1970-1979/decretolegislativo-74-30-junho-1977364249-publicacaooriginal-1-pl.html. Acesso em 21 de abril de 2020.

BRASIL. Decreto-Lei $\mathbf{n}^{\mathbf{0}} \mathbf{2 5}$, de 30 de novembro de 1937. Disponível em: http://www.planalto.gov.br/ccivil_03/decreto-lei/del0025.htm. Acesso em 30 de abril de 2020.

BRASIL. Decreto-Lei $\mathrm{n}^{\mathbf{0}} \mathbf{4 . 5 4 1}$, de 31 de julho de 1942. Disponível em: http://www.planalto.gov.br/ccivil_03/decreto-lei/1937-1946/Del4541.htm. Acesso em 29 de abril de 2020.

BRAZIL. Carioca Landscapes between the Mountain and the Sea - Rio de Janeiro World Heritage Nomination. 2011.P. 16 e Additional Information of the Rio de Janeiro Nomination as World Heritage. Disponível em: https://whc.unesco.org/uploads/nominations/1100rev.pdf. Acesso em 21 de abril de 2020. 
FRANCIONI, Francesco; GORDLEY, James. Enforcing International Cultural Heritage Law. Oxford: OUP, 2013, p.15.

INEPAC. Patrimônio Cultural de Bens Tombados. Disponível em: http://www.inepac.rj.gov.br/index.php/bens_tombados/detalhar/313 Acesso em 29 de abril de 2020.

STF. ADPF 206, Rel. Min. EDSON FACHIN, Decisão Monocrática, julgado em 09/03/2020, publicado em processo eletrônico. DJe-052 Divulgado em 10/03/2020, publicado em 11/03/2020.

STF. RE 1121517, Rel. Min. RICARDO LEWANDOWSKI, Decisão Monocrática,julgado em 30/04/2018, publicado em processo eletrônico. DJe-086 Divulgado em 03/05/2018, publicado em 04/05/2018.

STJ. RESP $\mathbf{n}^{\mathbf{o}}$ 1791098/RJ, Rel. Ministro HERMAN BENJAMIN, Segunda Turma. Julgado em 23/04/2019, DJe 02/08/2019

UNESCO. Operational Guidelines for the Implementation of the World Heritage Convention. Paris: UNESCO World Heritage Centre, 2019. P.15.

UNESCO. World Heritage Convention- State Parties Ratification Status. Disponível em: https://whc.unesco.org/en/statesparties/.Acesso em 21 de abril de 2020.

UNESCO. World Heritage List. Disponível em: https://whc.unesco.org/en/list/. Acesso em 21 de abril de 2020.

Comentário recebido em: 03/09/2020.

Aceito para publicação em: 30/04/2020. 